\title{
A GENERALIZED EXPRESSION FOR RESONANT FREQUENCY OF CIRCULAR MICROSTRIP ANTENNAS
}

\author{
Rajanish , Student Member, IEEE and T. S. Vedavathy \\ Electrical Communication Engineering Department \\ Indian Institute of Science, Bangalore, India. \\ E-mail: rajanish@protocol.ece.iisc.ernet.in \\ veda@ece.iisc.ernet.in
}

\begin{abstract}
A generalized expression for calculating the resonant frequency of microstrip antennas is presented. The analysis includes the correction factor for higher order modes to obtain the generalized expression for the resonant frequency in the cavity model analysis. Multilayer dielectric circular patch antennas with and without airgap are analyzed using effective quasi-static capacitance approach and compared with the experimental results to show the versatility of the proposed generalization in achieving near to accurate result with more than four fold accuracy as compared to the dominant mode expression.
\end{abstract}

\section{Introduction}

In the recent past the use of microstrip antennas has acquired a steep ascent in the various applications due to its versatile characteristics, viz. compactness, conformal nature, etc. Moreover, applications for higher order modes have also emerged such as GPS receivers, etc. But, at the same time, it has its inherent limitations of smaller bandwidth. Of the various solutions suggested for the improvement in the bandwidth, in the literature, stack of layered dielectrics with air-gap introduced, is promising one for the lightweight arrays onboard satellites.

Various analyses [1]-[3] have been carried out to determine the resonant frequency of the microstrip antennas, but lack accuracy while determining the resonant frequency of higher order modes. In this paper, as first part, modified capacitance, which takes care of the fringe field variations due to different modes is formulated as in [4]. Then, the layered dielectric circular patch antennas, viz., disks and annular rings, with and without air-gap are analyzed by calculating the effective capacitance by quasi-static capacitance approach.

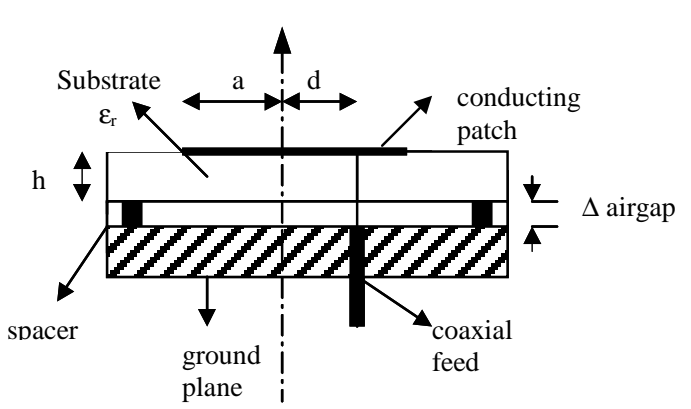

Fig. 1. Circular disc microstrip antenna with air-gap

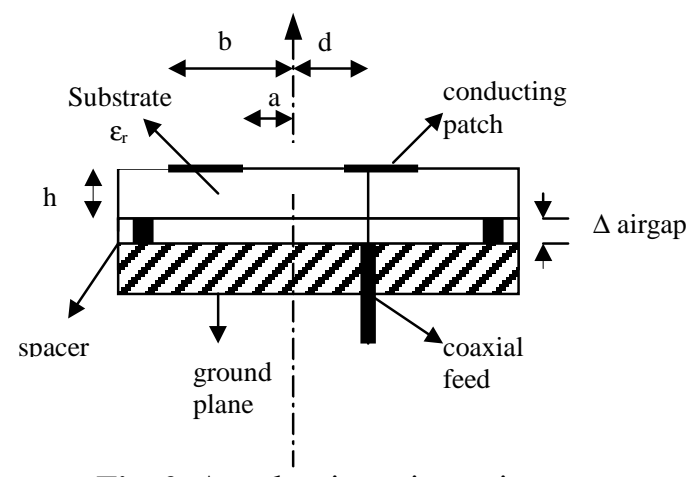

Fig. 2. Annular ring microstrip antenna with air-gap 


\section{Analysis}

\subsection{Disk Antenna}

The resonant frequency of microstrip antenna is governed by the accuracy of the capacitance of the patch resonator and is given by [2]

$$
f^{(1)}=\frac{1}{2 \pi \sqrt{L^{(1)} C^{(1)}(1+\Delta)}}
$$

where, for small h/a,

$$
\Delta=\frac{2 h}{\pi a \varepsilon_{r}}\left(\ln \frac{\pi a}{2 h}+1.7726\right) \quad\left\{\begin{array}{l}
\mathrm{h} \equiv \text { height of the substrate } \\
\varepsilon \equiv \text { dielectric constant of the substrate } \\
\mathrm{a} \equiv \text { radius of the disk }
\end{array}\right.
$$

where, $\mathrm{L}^{(1)}$ and $\mathrm{C}^{(1)}$ are first order inductance and capacitance, respectively.

But, it is observed from the experimental results that these formulas provide comparable results only for the dominant modes. Using the same formula for calculating the resonant frequency of higher order modes, gives a considerable drift between theoretical and measured value. Hence, the capacitance also needs to incorporate the fringe field variations and hence the mode variables, $n$ and $m$ to yield a better accuracy, where, $n$ is the order of the Bessel function and, $m$ is $m^{\text {th }}$ zero of the function $J n^{\prime}(k a)$. Thus, the logarithmic term (2) is modified for a better approximation of capacitance for the higher order modes as,

$$
\Delta=\frac{2 h}{\pi a \varepsilon_{r}}\left(\ln \frac{\pi a}{2 h} F(n, m)+1.7726\right)
$$

where,

$$
\begin{aligned}
& F(n, m)=f(n, m) * g(\beta)^{q} \\
& f(n, m)=(\beta / \alpha)^{k} \\
& \begin{array}{l}
\alpha= \begin{cases}\mathrm{n}, & \mathrm{n} \geq 1 \\
1, & \mathrm{n}=0\end{cases} \\
\beta=\mathrm{m} \quad \forall \mathrm{m}
\end{array}
\end{aligned}
$$

The value of $k$ is obtained in the least square error sense and, is approximately equal to 2 . Then, the function $g(\beta)=\beta$, is optimised for minimum error for which we obtain $q \approx 1$.Thus, the general formula of capacitance for any mode can be given by,

$$
C^{(1)}=C^{(0)}\left[1+\frac{2 h}{\pi a \varepsilon_{r}}\left(\ln \frac{\pi a}{2 h \alpha^{2}} \cdot \beta^{3}+1.7726\right)\right]
$$

\subsection{Annular Ring Antenna}

The modified first order capacitance is applied to the annular ring antenna by considering the inner and outer radiating circular edges as edges of disc of smaller and larger radii, respectively, giving modified ' $a$ ' and ' $b$ ' as

$a_{\text {eff }}=a\left[1-\frac{2 h}{\pi a \varepsilon_{\text {eff }}}\left(\ln \frac{\pi a}{2 h \alpha^{2}} \cdot \beta^{3}+1.7726\right)\right]^{1 / 2} ; b_{\text {eff }}=b\left[1+\frac{2 h}{\pi b \varepsilon_{\text {eff }}}\left(\ln \frac{\pi b}{2 h \alpha^{2}} \cdot \beta^{3}+1.7726\right)\right]^{1 / 2}$

\subsection{Patch Antenna with Air Gap}

The capacitance is a function of only the dielectrics and the geometry of the patch. If we assume a potential difference of $\mathrm{V}_{0}$ between the plates and uniform electric field intensities in the two regions with electric flux densities $D_{1}=D_{2}$ (as the magnitude of the surface charge, $\mathrm{Q}$, is same), the effective capacitance is 
$C=Q / V_{0}=\rho_{s} A / V_{0}=1 /\left[h_{1} / \varepsilon_{1} A+h_{2} / \varepsilon_{2} A\right]=1 /\left[1 / C_{1}+1 / C_{2}\right]$

i.e., the individual capacitance are in series.

To calculate the resonant frequency of the disk, the effective dielectric constant is calculated as $\varepsilon_{\text {eff }}=C\left(h_{1}+h_{2}\right) / A$. where, $C$ is the series capacitance of the layers. To calculate the resonant frequency of annular ring with an air gap, effective inner and outer radii are calculated using the effective dielectric constant formula. Then the patch area responsible for the capacitance of each layer is calculated, i.e., $A=\pi\left(b^{2} e_{\text {eff }}-a^{2}\right.$ eff $)$. The series capacitance is obtained and then the same step is followed as for finding the resonant frequency of the circular disk.

\section{Results and Discussion}

Resonant frequencies of circular and annular ring antennas with and without airgap for dominant as well as higher order modes are compared with the experimental and theoretical results reported in the literature by Lee and Dahele [3]. We see a large improvement over the conventional analysis. It is found that the error between theoretical and experimental values is minimal and gives more than four fold accuracy as compared to [3].

\begin{tabular}{|c|c|c|c|c|c|}
\hline MODE & $\begin{array}{c}\text { Experimental } \\
\text { Value } \\
(\mathrm{GHz})\end{array}$ & $\begin{array}{c}\text { Theoretical } \\
\text { Results [3] } \\
(\mathrm{GHz})\end{array}$ & $\begin{array}{c}\% \\
\text { Error }\end{array}$ & $\begin{array}{c}\text { Proposed } \\
\text { Method } \\
(\mathrm{GHz})\end{array}$ & $\begin{array}{c}\% \\
\text { Error }\end{array}$ \\
\hline $\mathrm{TM}_{11}$ & 1.128 & 1.127 & .11 & 1.127 & .11 \\
\hline $\mathrm{TM}_{21}$ & 1.879 & 1.869 & .53 & 1.880 & .06 \\
\hline $\mathrm{TM}_{31}$ & 2.596 & 2.571 & .96 & 2.595 & .05 \\
\hline
\end{tabular}

$a=5.0 \mathrm{~cm}, h=0.159 \mathrm{~cm}, d=4.75 \mathrm{~cm}, \varepsilon_{r}=2.32$

Table 1. Comparison of calculated and measured resonant frequencies of disk antennas

Air gap Thickness, $h_{11}=0.5 \mathrm{~mm}$

\begin{tabular}{|l|c|c|c|c|c|c|c|c|c|c|}
\hline & $\begin{array}{c}\text { Exp. } \\
\text { Value } \\
(\mathrm{GHz})\end{array}$ & $\begin{array}{c}\text { Ref. [3] } \\
(\mathrm{GHz})\end{array}$ & $\begin{array}{c}\% \\
\text { Err. }\end{array}$ & $\begin{array}{c}\text { Prop. } \\
\text { Meth. } \\
(\mathrm{GHz})\end{array}$ & $\begin{array}{c}\% \\
\text { Err. }\end{array}$ & $\begin{array}{c}\text { Exp. } \\
\text { Value } \\
(\mathrm{GHz})\end{array}$ & $\begin{array}{c}\text { Ref. [3] } \\
(\mathrm{GHz})\end{array}$ & $\begin{array}{c}\% \\
\text { Err. }\end{array}$ & $\begin{array}{c}\text { Prop. } \\
\text { Meth. } \\
(\mathrm{GHz})\end{array}$ & $\begin{array}{c}\text { \% } \\
\text { Err. }\end{array}$ \\
\hline $\mathrm{T} \mathrm{M}_{11}$ & 1.286 & 1.276 & .78 & 1.277 & .69 & 1.350 & 1.351 & .07 & 1.351 & .07 \\
\hline $\mathrm{T} \mathrm{M}_{21}$ & 2.136 & 2.117 & .89 & 2.133 & .14 & 2.256 & 2.241 & .66 & 2.262 & .28 \\
\hline $\mathrm{T} \mathrm{M}_{31}$ & 2.951 & 2.911 & 1.36 & 2.951 & .00 & 3.106 & 3.082 & .77 & 3.127 & .67 \\
\hline
\end{tabular}

$a=5.0 \mathrm{~cm}, h=0.159 \mathrm{~cm}, d=4.75 \mathrm{~cm}, \varepsilon_{r}=2.32$

Table 2. Comparison of calculated and measured resonant freq. of disk antennas with air gap

\begin{tabular}{|c|c|c|c|c|c|}
\hline MODE & $\begin{array}{c}\text { Experimental } \\
\text { Value } \\
(\mathrm{MHz})\end{array}$ & $\begin{array}{c}\text { Theoretical } \\
\text { Results [3] } \\
(\mathrm{MHz})\end{array}$ & $\begin{array}{c}\% \\
\text { Error }\end{array}$ & $\begin{array}{c}\text { Proposed } \\
\text { Method } \\
(\mathrm{MHz})\end{array}$ & $\begin{array}{c}\text { \% } \\
\text { Error }\end{array}$ \\
\hline $\mathrm{T} \mathrm{M}_{11}$ & 626 & 622 & .64 & 622 & .64 \\
\hline $\mathrm{T} \mathrm{M}_{21}$ & 1229 & 1220 & .73 & 1228 & .08 \\
\hline $\mathrm{T} \mathrm{M}_{31}$ & 1800 & 1793 & .39 & 1801 & .06 \\
\hline $\mathrm{T} \mathrm{M}_{12}$ & 2757 & 2820 & 2.29 & 2764 & .25 \\
\hline
\end{tabular}

$\mathrm{a}=3.5 \mathrm{~cm}, \mathrm{~b}=7.0 \mathrm{~cm}, \mathrm{~h}=0.159 \mathrm{~cm}, \mathrm{~d}=3.6 \mathrm{~cm}, \varepsilon_{\mathrm{r}}=2.32$

Table 3. Comparison of calculated and measured resonant frequencies of ring antennas 


\begin{tabular}{|c|c|c|c|c|c|c|c|c|c|c|}
\multicolumn{1}{c|}{ Air gap Thickness, $h_{11}=0.5 \mathrm{~mm}$} & \multicolumn{10}{c|}{ Air gap Thickness, $h_{11}=1.0 \mathrm{~mm}$} \\
\hline & $\begin{array}{c}\text { Exp. } \\
\text { Value } \\
(\mathrm{MHz})\end{array}$ & $\begin{array}{c}\text { Ref. } \\
{[3]} \\
(\mathrm{MHz})\end{array}$ & $\begin{array}{c}\% \\
\text { Err. }\end{array}$ & $\begin{array}{c}\text { Prop. } \\
\text { Meth. } \\
(\mathrm{MHz})\end{array}$ & $\begin{array}{c}\% \\
\text { Err. }\end{array}$ & $\begin{array}{c}\text { Exp. } \\
\text { Value } \\
(\mathrm{MHz})\end{array}$ & $\begin{array}{c}\text { Ref. } \\
{[3]} \\
(\mathrm{MHz})\end{array}$ & $\begin{array}{c}\% \\
\text { Err. }\end{array}$ & $\begin{array}{c}\text { Prop. } \\
\text { Meth. } \\
(\mathrm{MHz})\end{array}$ & $\begin{array}{c}\% \\
\text { Err. }\end{array}$ \\
$\mathrm{MODE}$ & & & & & & & & & \\
\hline $\mathrm{T} \mathrm{M}_{11}$ & 720 & 714 & .83 & 722 & .27 & 778 & 763 & 1.93 & 771 & .90 \\
\hline $\mathrm{T} \mathrm{M}_{21}$ & 1415 & 1405 & .71 & 1422 & .49 & 1516 & 1498 & 1.18 & 1513 & .19 \\
\hline $\mathrm{T} \mathrm{M}_{31}$ & 2075 & 2057 & .87 & 2091 & .77 & 2212 & 2185 & 1.22 & 2220 & .36 \\
\hline
\end{tabular}

$\mathrm{a}=3.5 \mathrm{~cm}, \mathrm{~b}=7.0 \mathrm{~cm}, \mathrm{~h}=0.159 \mathrm{~cm}, \mathrm{~d}=3.6 \mathrm{~cm}, \varepsilon_{\mathrm{r}}=2.32$

Table 4. Comparison of calculated and measured resonant freq. of ring antennas with air gap

\section{Conclusion}

Modified expression for the calculation of the resonant frequency of microstrip patch antennas is presented which incorporates the mode variables to account for the fringing field variations due to different modes which gives the improved accuracy at all modes of excitation. Effective capacitance technique considering multilayer dielectric patch antenna as a parallel configured quasi-static capacitance shows a simple and efficient analysis to calculate the resonant frequency of multilayer dielectric microstrip antennas. Validation of various experimental results with the proposed theory confirms the improved accuracy.

\section{References}

[1] P. Myhili and A. Das, "Simple approach to determine the resonant frequencies of microstrip antennas," IEE Proc. Pt. H, Vol. 145, No.2, pp. 159-162, April 1998

[2] L. C. Shen, S. A. Long, M. R. Allerding and M. D. Walton, "Resonant frequency of a circular disc. printed circuit antenna," IEEE Trans. AP, pp. 595-596, July 1979.

[3] J. S. Dahele and Kai F. Lee, "Theory and experiment on microstrip antennas with airgaps," IEE Proc. Pt. H, no. 7 , pp. 455-460, Dec. 1985.

[4]. Rajanish and T.S. Vedavathy, "Resonant frequency of higher order modes for circular microstrip antennas”, 1999 Asia Pacific Microwave Conference (AMPC'99), pp. 936-940. 